Address for Correspondence: Prof. Xiaozhong Guo and Dr. Xingshun Qi, Department of Gastroenterology, General Hospital of Shenyang Military Area, No. 83 Wenhua Road, Shenyang 110031, Liaoning Province, China. Email: guo xiao zhong@126.com (Xiaozhong Guo):

xingshunqi@126.com (Xingshun Qi)

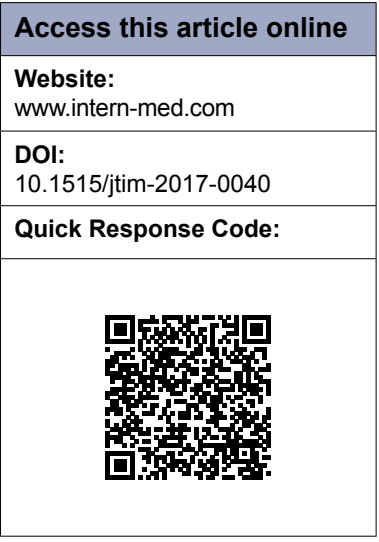

\title{
Should vasoconstrictors be considered in a cirrhotic patient with acute non-variceal upper gastrointestinal bleeding?
}

\author{
Xingshun Qi ${ }^{1}$, Hongyu $\mathrm{Li}^{1}$, Xiaodong Shao ${ }^{1}$, Zhendong Liang ${ }^{1}$, \\ Xia Zhang ${ }^{2}$, Ji Feng ${ }^{1}$, Hao Lin ${ }^{1}$, Xiaozhong Guo ${ }^{1}$ \\ 'Liver Cirrhosis Study Group, Department of Gastroenterology, General Hospital of Shenyang Military Area, \\ Shenyang 110840, Liaoning Province, China; \\ ${ }^{2}$ No. 4 People Hospital of Shenyang City, Shenyang 110031, Liaoning Province, China
}

\section{ABSTRACT}

Varices manifest as a major etiology of upper gastrointestinal bleeding in patients with chronic liver diseases, such as liver cirrhosis and hepatocellular carcinoma. By contrast, non-variceal upper gastrointestinal bleeding is rare. Pharmacological treatment differs between patients with variceal and non-variceal bleeding. Vasoconstrictors are recommended for the treatment of variceal bleeding, rather than non-variceal bleeding. In contrast, pump proton inhibitors are recommended for the treatment of non-variceal bleeding, rather than variceal bleeding. Herein, we present a case with liver cirrhosis and acute upper gastrointestinal bleeding who had a high risk of rebleeding (i.e., Child-Pugh class $\mathrm{C}$, hepatocellular carcinoma, portal vein thrombosis, low albumin, and high international normalized ratio and D-dimer). As the source of bleeding was obscure, only terlipressin without pump proton inhibitors was initially administered. Acute bleeding episode was effectively controlled. After that, an elective endoscopic examination confirmed that the source of bleeding was attributed to peptic ulcer, rather than varices. Based on this preliminary case report, we further discussed the potential role of vasoconstrictors in a patient with cirrhosis with acute non-variceal upper gastrointestinal bleeding.

Key words: varices, bleeding, cirrhosis, liver, terlipressin

\section{INTRODUCTION}

Acute upper gastrointestinal bleeding in liver cirrhosis is mainly attributed to the development of variceal rupture ${ }^{[1-4]}$. The first-line choice of pharmacological therapy for the management of variceal bleeding is vasoconstrictors, including terlipressin, somatostatin, and octreotide ${ }^{[1-2]}$. The use of pump proton inhibitors is compromised for the management of variceal bleeding in liver cirrhosis according to the current UK guidelines ${ }^{[5]}$. By comparison, a small proportion of acute upper gastrointestinal bleeding episodes in liver cirrhosis are attributed to the peptic ulcer or other non-variceal sources ${ }^{[-7]}$, in which case pump proton inhibitors are the standard choice of therapy. Here, we report a case with liver cirrhosis and non-variceal upper gastrointestinal bleeding that was effectively controlled by terlipressin alone without pump proton inhibitors. We also discuss the timing and indication of vasoconstrictors for non-variceal upper gastrointestinal bleeding in liver cirrhosis.

\section{CASE PRESENTATION}

On February 24, 2017, a 45-year-old male was admitted to our hospital due to intermittent melena for about one month. Two years ago, he was diagnosed with hepatitis B virus infection and was treated with entecavir. At that time, he was also diagnosed with liver cirrhosis and hepatocellular carcinoma and was treated with external radiation therapy and transarterial chemoembolization. About 2 months ago, he underwent abdominal contrast-enhanced computed tomography, which showed an occlusion at the left 
portal vein branch, patent right portal vein branches, main portal vein, and superior mesenteric vein, esophageal and gastric varices, splenomegaly, lipiodol deposition at hepatic lesions, and no asictes (Figure 1). Splenorenal shunt was also observed in the computed tomography scans (Figure 2). He denied any history of alcohol abuse. He had a longterm history of unknown drugs for psoriasis. At the time of this admission, physical examination demonstrated jaundice, splenomegaly, and positive shifting dullness. Laboratory tests demonstrated that white blood cell count was $11.8 \times 10^{9} / \mathrm{L}$ (reference range: $3.5-9.5 \times 10^{9} / \mathrm{L}$ ), hemoglobin was $57 \mathrm{~g} / \mathrm{L}$ (reference range: 130-175 g/L), platelet count was $99 \times 10^{9} / \mathrm{L}$ (reference range: 125 $350 \times 10^{9} / \mathrm{L}$ ), international normalized ratio was 2.02 , and total bilirubin was $92.3 \mu \mathrm{mol} / \mathrm{L}$ (reference range: 5.1-22.2 $\mu \mathrm{mol} / \mathrm{L})$. Abdominal plain computed tomography CT scans demonstrated massive ascites, splenomegaly, and lipiodol deposition at hepatic lesions (Figure 3). At our department, he received a continuous intravenous infusion of terlipressin $1 \mathrm{mg}$ per $6 \mathrm{~h}$ and intravenous infusion of cefatriaxone $1 \mathrm{~g}$ per day except for blood transfusion. No other vasoconstrictors were given. No anti-acid drugs were

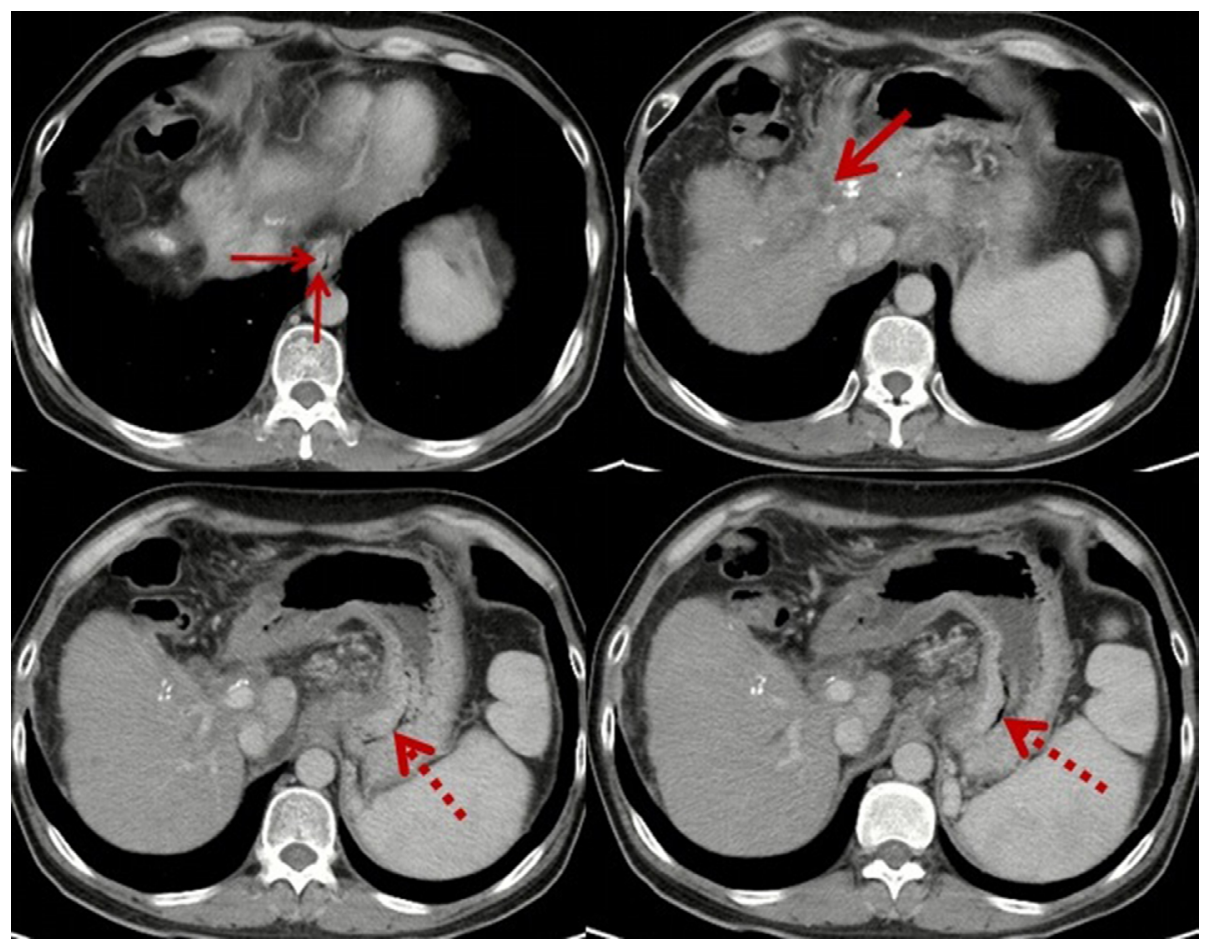

Figure 1: Abdominal contrast-enhanced computed tomography scans performed 2 months ago. Thin solid arrows represent esophageal varices. Thick solid arrows represent an occlusion at the left portal vein branch. Thick dotted arrows represent gastric varices.

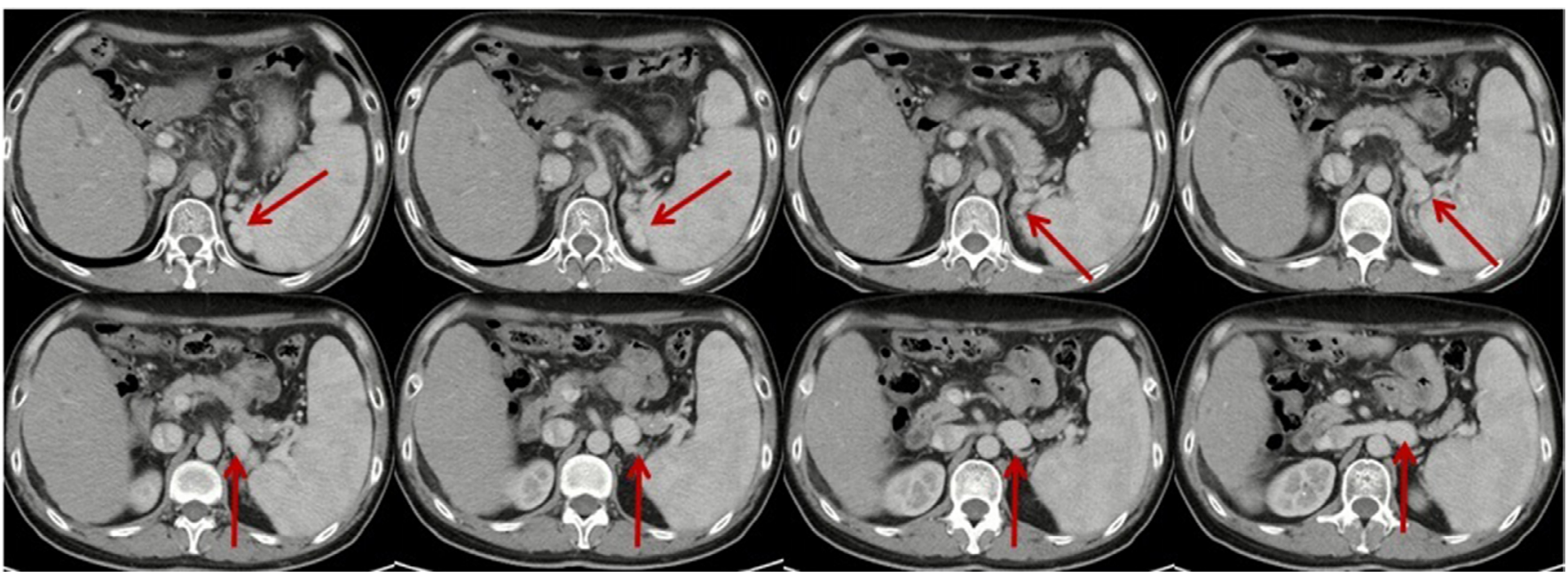

Figure 2: Abdominal contrast-enhanced computed tomography scans performed 2 months ago showing splenorenal shunt. Arrows represent splenorenal shunt. 
given. On February 26, 2017, laboratory tests showed that white blood cell count was $3.1 \times 10^{9} / \mathrm{L}$, hemoglobin was 69 $\mathrm{g} / \mathrm{L}$, platelet count was $56 \times 10^{9} / \mathrm{L}$, international normalized ratio was 1.6, total bilirubin was $93.3 \mu \mathrm{mol} / \mathrm{L}$, albumin was $18.7 \mathrm{~g} / \mathrm{L}$ (reference range: $40-55 \mathrm{~g} / \mathrm{L}$ ), creatinine was $59.06 \mu \mathrm{mol} / \mathrm{L}$ (reference range: $44-133 \mu \mathrm{mol} / \mathrm{L}$ ), alpha feto-protein was $121.5 \mathrm{ng} / \mathrm{mL}$ (reference range: $0-10 \mathrm{ng}$ / $\mathrm{mL}$ ), and stool occult blood was positive. At that time, he had a Child-Pugh class C. After that, his melena gradually stopped. He underwent abdominocentesis and received diuretics and supplementation of albumin. On February 28, 2017, laboratory tests gave the following results: white blood cell was $2.3 \times 10^{9} / \mathrm{L}$, hemoglobin was $79 \mathrm{~g} / \mathrm{L}$, platelet count was $55 \times 10^{9} / \mathrm{L}$, international normalized ratio was 1.47 , total bilirubin was $51.9 \mu \mathrm{mol} / \mathrm{L}$, albumin was $21.9 \mathrm{~g} / \mathrm{L}$, creatinine was $41 \mu \mathrm{mol} / \mathrm{L}$, and stool occult blood became negative. Considering that gastrointestinal bleeding was effectively controlled, administration of terlipressin was stopped. On March 3, 2017, an elective upper gastrointestinal endoscopy was performed, showing mild esophageal varices without red color sign, gastric ulcer in the antrum with an oozing blood (Forrest Ib), and gastric antral vascular ectasias (Figure 4). Thus, a continuous infusion of esomeprazole $80 \mathrm{mg}$ per $10 \mathrm{~h}$ was given. On March 8, 2017, laboratory tests demonstrated that white blood cell was $2.1 \times 10^{\circ} / \mathrm{L}$, hemoglobin was 78 $\mathrm{g} / \mathrm{L}$, platelet count was $37 \times 10^{9} / \mathrm{L}$, international normalized ratio was 1.47 , total bilirubin was $39.2 \mu \mathrm{mol} / \mathrm{L}$, albumin was $26.7 \mathrm{~g} / \mathrm{L}$, creatinine was $55.68 \mu \mathrm{mol} / \mathrm{L}$, and stool occult blood became negative. After that, he was discharged. Oral esomeprazole was prescribed for at least 6 weeks.

\section{DISCUSSION}

An endoscopic examination is recommended within $12 \mathrm{~h}$ after an acute upper gastrointestinal bleeding episode, if

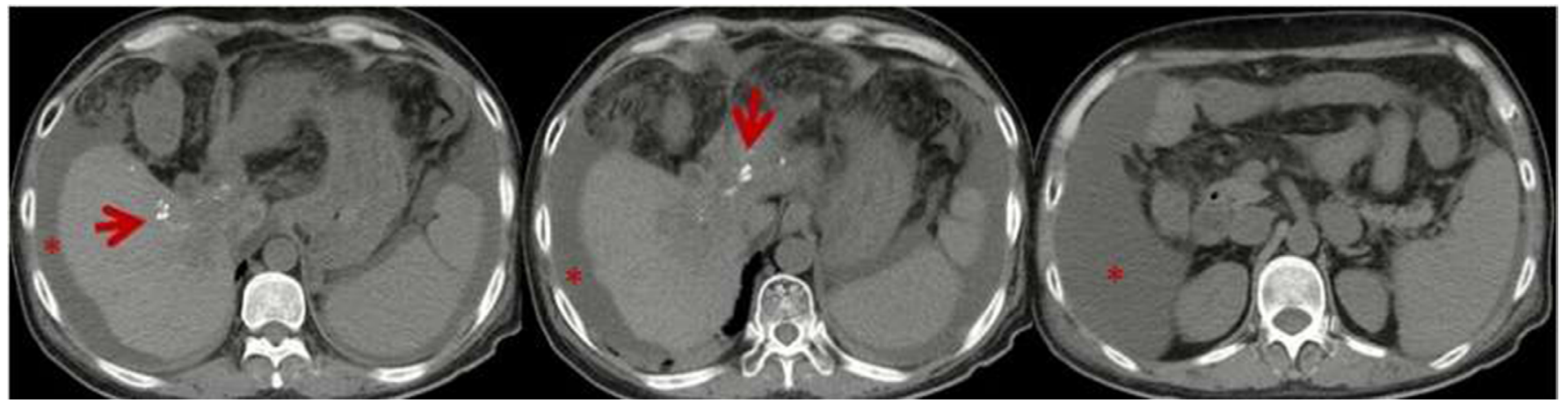

Figure 3. Abdominal plain computed tomography scans performed at this admission. Asterisks represent massive ascites.

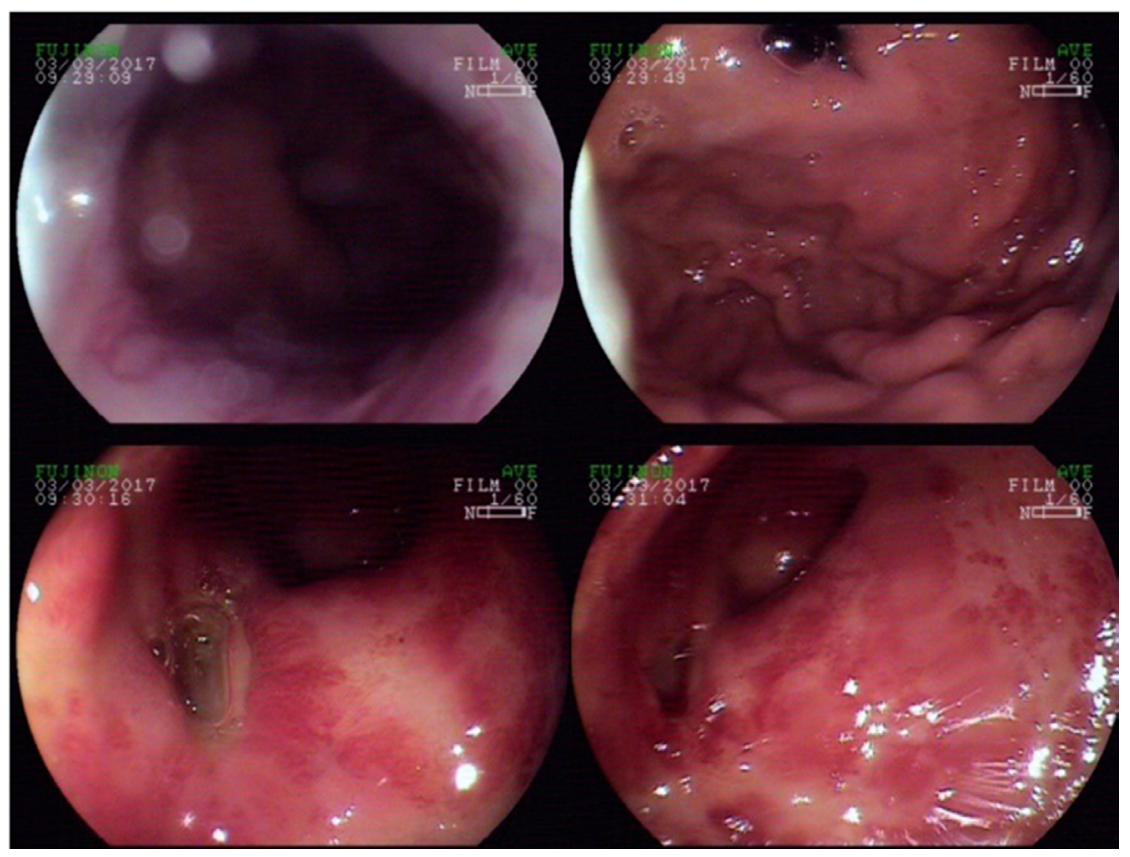

Figure 4. Endoscopic examinations performed at this admission. Upper left panel: mild esophageal varices. Upper right panel: no obvious gastric varices. Lower left panel: gastric ulcer. Lower right panel: gastric antral vascular ectasias. 
the hemodynamic condition is stable ${ }^{[8]}$. However, it was difficult to perform an urgent endoscopy in our patient. The reasons why our patient did not undergo an urgent endoscopy included: (1) he had a very low albumin and high international normalized ratio and d-dimer, which were significantly associated with a higher risk of 5-day bleeding in cirrhotic patients treated with endoscopic therapy ${ }^{[0]}$; (2) he had a prior diagnosis of hepatocellular carcinoma and portal vein thrombus, which are the independent predictors for worse outcomes after endoscopic therapy ${ }^{[10]}$; (3) he had a Child-Pugh class $\mathrm{C}$, which is an important predictor for rebleeding after endoscopic therapy ${ }^{[11]}$; (4) considering that pharmacological therapy is effective in our patient, an elective endoscopic therapy is considered to have a lower risk; (5) timing of endoscopy is not associated with the outcomes of non-hematemesis patients with active esophageal variceal bleeding ${ }^{[10]}$; and (6) our patient and his relatives were reluctant to undergo an endoscopy at his admission.

The most common source of upper gastrointestinal bleeding in patients with liver cirrhosis is variceal rupture. Notably, a contrast-enhanced computed tomography performed 2 months ago in our patient indicated the probability of esophageal and gastric varices. Thus, a diagnosis of variceal bleeding was initially considered. Proton pump inhibitors are not recommended for the treatment of variceal bleeding in liver cirrhosis ${ }^{[5]}$. Thus, we did not prescribe proton pump inhibitors to this patient at his admission.

An important finding of our case report is that terlipressin may effectively control peptic ulcer bleeding in the absence of proton pump inhibitors. However, this is just a case with a high degree of probability chance, so we need to cautiously interpret the finding and review the current recommendations and potential mechanisms.

In the current guidelines and consensus regarding the management of non-variceal upper gastrointestinal bleeding, high-dose proton pump inhibitors are the firstline choice of therapy ${ }^{[12,13]}$, but the use of vasoconstrictors (i.e., terlipressin, somatostatin, and octreotide), which have been approved for the management of variceal bleeding ${ }^{[5]}$, is rarely mentioned. By comparison, earlier guidelines and reviews suggest that somatostatin should be effective for controlling the non-variceal upper gastrointestinal bleeding ${ }^{[14-15]}$, which is primarily attributed to the results of an early meta-analysis comparing the outcomes of somatostatin or octreotide versus $\mathrm{H}_{2}$ antagonists or placebo for the treatment of non-variceal upper gastrointestinal bleeding ${ }^{[16]}$. But some experts argued that the trials included in the meta-analysis employed the outdated diagnostic and therapeutic approaches ${ }^{[17]}$. A retrospective study also found no significant benefit of adjunctive somatostatin in patients with non-variceal upper gastrointestinal bleeding treated with pantoprazole ${ }^{[18]}$. Therefore, based on the current evidence regarding the use of vasoconstrictors for the management of non-variceal upper gastrointestinal bleeding ${ }^{[19]}$, somatostatin could be considered in only selective cases with severely acute non-variceal upper gastrointestinal bleeding. This consideration is consistent with the drug usage instructions. Notably, to our knowledge, no evidence regarding use of terlipressin in such patients was established.

The mechanisms of somatostatin for controlling nonvariceal upper gastrointestinal bleeding may include the following: (1) it can significantly decrease the portal venous volume flow and superior mesenteric arterial average flow velocity, which significantly correlate with the risk of rebleeding in patients with peptic ulcer bleeding ${ }^{[20]}$ and (2) it can maintain a significantly higher percentage of time spent above a $\mathrm{pH}$ threshold of $>4.0$ or $>5.4$ in the fundus than pantoprazole ${ }^{[2]}$. Whether these benefits of somatostatin for the management of non-variceal upper gastrointestinal bleeding can be extrapolated to terlipressin is uncertain. As well known, terlipressin has a similar effect of reducing the splanchnic blood flow ${ }^{[22]}$. But we have to acknowledge that no information exists on its effect on gastric acid secretion. Further studies might be necessary to explore the potential role of terlipressin in the management of non-variceal upper gastrointestinal bleeding.

Based on this preliminary case report, we proposed a clinical problem regarding the timing and indication of vasoconstrictors in patients with chronic liver diseases and upper gastrointestinal bleeding where the source of bleeding is obscure. This is very important because the source of bleeding cannot be readily identified in primary hospitals or clinical situations where endoscopic examinations are unavailable. Further randomized controlled trials and experimental studies should be warranted.

\section{Conflict of interests}

\section{None}

\section{REFERENCES}

1. Garcia-Tsao G, Bosch J. Management of varices and variceal hemorrhage in cirrhosis. N Engl J Med 2010; 362: 823-32.

2. Toshikuni N, Takuma Y, Tsutsumi M. Management of gastroesophageal varices in cirrhotic patients: current status and future directions. Ann Hepatol 2016; 15: 314-25.

3. Peng Y, Qi X, Dai J, Li H, Guo X. Child-Pugh versus MELD score for predicting the in-hospital mortality of acute upper gastrointestinal bleeding in liver cirrhosis. Int J Clin Exp Med 2015; 8: 751-7.

4. Zou D, Qi X, Zhu C, Ning Z, Hou F, Zhao J, et al. Albumin-bilirubin score for predicting the in-hospital mortality of acute upper gastrointestinal 
bleeding in liver cirrhosis: A retrospective study. Turk J Gastroenterol 2016; 27: 180-6.

5. Tripathi D, Stanley AJ, Hayes PC, Patch D, Millson C, Mehrzad H, et al. UK guidelines on the management of variceal haemorrhage in cirrhotic patients. Gut 2015; 64: 1680-704.

6. Gabr MA, Tawfik MA, El-Sawy AA. Non-variceal upper gastrointestinal bleeding in cirrhotic patients in Nile Delta. Indian J Gastroenterol 2016; 35: 25-32.

7. Gonzalez-Gonzalez JA, Garcia-Compean D, Vazquez-Elizondo G, GarzaGalindo A, Jaquez-Quintana JO, Maldonado-Garza H. Nonvariceal upper gastrointestinal bleeding in patients with liver cirrhosis. Clinical features, outcomes and predictors of in-hospital mortality. A prospective study. Ann Hepatol 2011; 10: 287-95.

8. de Franchis R. Expanding consensus in portal hypertension: Report of the Baveno VI Consensus Workshop: Stratifying risk and individualizing care for portal hypertension. J Hepatol 2015; 63: 743-52.

9. Sun R, Qi X, Zou D, Shao X, Li H, Guo X. Risk factors for 5-day bleeding after endoscopic treatments for gastroesophageal varices in liver cirrhosis. AME Med J 2017; 2: 39.

10. Chen PH, Chen WC, Hou MC, Liu TT, Chang CJ, Liao WC, et al. Delayed endoscopy increases re-bleeding and mortality in patients with hematemesis and active esophageal variceal bleeding: a cohort study. J Hepatol 2012; 57: 1207-13.

11. Garcia-Tsao G, Abraldes JG, Berzigotti A, Bosch J. Portal hypertensive bleeding in cirrhosis: Risk stratification, diagnosis, and management: 2016 practice guidance by the American Association for the study of liver diseases. Hepatology 2017; 65: 310-35.

12. Laine L, Jensen DM. Management of patients with ulcer bleeding. Am J Gastroenterol 2012; 107: 345-60; quiz 61.

13. Sung JJ, Chan FK, Chen M, Ching JY, Ho KY, Kachintorn U, et al. AsiaPacific Working Group consensus on non-variceal upper gastrointestinal bleeding. Gut 2011; 60: 1170-7.

14. Non-variceal upper gastrointestinal haemorrhage: guidelines. Gut 2002; 51(Suppl 4): iv1-6.
15. Jenkins SA, Poulianos G, Coraggio F, Rotondano G. Somatostatin in the treatment of non-variceal upper gastrointestinal bleeding. Dig Dis 1998; 16: 214-24.

16. Imperiale $\mathrm{TF}$, Birgisson S. Somatostatin or octreotide compared with $\mathrm{H} 2$ antagonists and placebo in the management of acute nonvariceal upper gastrointestinal hemorrhage: a meta-analysis. Ann Intern Med 1997; 127: 1062-71.

17. Greenspoon J, Barkun A. The pharmacological therapy of non-variceal upper gastrointestinal bleeding. Gastroenterol Clin North Am 2010; 39: 419-32.

18. Choi CW, Kang DH, Kim HW, Park SB, Park KT, Kim GH, et al. Somatostatin adjunctive therapy for non-variceal upper gastrointestinal rebleeding after endoscopic therapy. World J Gastroenterol 2011; 17: 3441-7.

19. May G, Butler J. Towards evidence based emergency medicine: best BETs from the Manchester Royal Infirmary. The use of vasoconstrictor therapy in non-variceal upper GI bleeds. Emerg Med J. 2006; 23: 722-4.

20. Saruc M, Can M, Kucukmetin N, Tuzcuoglu I, Tarhan S, Goktan C, et al. Somatostatin infusion and hemodynamic changes in patients with non-variceal upper gastrointestinal bleeding: a pilot study. Med Sci Monit 2003; 9: PI84-7.

21. Avgerinos A, Sgouros S, Viazis N, Vlachogiannakos J, Papaxoinis K, Bergele $\mathrm{C}$, et al. Somatostatin inhibits gastric acid secretion more effectively than pantoprazole in patients with peptic ulcer bleeding: a prospective, randomized, placebo-controlled trial. Scand J Gastroenterol 2005; 40: 515-22.

22. Kam PC, Williams S, Yoong FF. Vasopressin and terlipressin: pharmacology and its clinical relevance. Anaesthesia 2004; 59: 993-1001.

How to cite this article: Qi X, Li H, Shao X, Liang Z, Zhang Z, Feng J, et al. Should vasoconstrictors be considered in a cirrhotic patient with acute non-variceal upper gastrointestinal bleeding? J Transl Intern Med 2017; 5: 240-4. 